\title{
BMJ Open Australian mental health caregiver burden: a smallest space analysis
}

To cite: Morrison P, Stomski NJ. Australian mental health caregiver burden: a smallest space analysis. BMJ Open 2019;9:e022419. doi:10.1136/ bmjopen-2018-022419

- Prepublication history for this paper is available online To view these files, please visit the journal online (http://dx.doi org/10.1136/bmjopen-2018022419).

Received 18 February 2018 Revised 15 March 2019 Accepted 7 May 2019
Check for updates

(C) Author(s) (or their employer(s)) 2019. Re-use permitted under CC BY-NC. No commercial re-use. See rights and permissions. Published by BMJ.

College of Science, Health, Engineering and Education, Murdoch University, Murdoch, Western Australia, Australia

Correspondence to Dr Norman Jay Stomski; N.Stomski@murdoch.edu.au

\section{ABSTRACT}

Objectives To explore Australian mental health carers' prioritisation of key elements of caregiving and establish the extent to which particular issues contribute to carer burden.

Design Cross-sectional survey.

Setting All Australian States and Territories.

Participants Responses were received from 231

Australian mental health caregivers.

Main outcome measures The Involvement Evaluation Questionnaire was used to assess caregiver burden. Results Smallest space analysis identified three distinct regions, which we conceptualise as: 1) promoting the safety and health of mental health consumers; 2) impact of caring on caregivers' personal lives and 3 ) enabling daily living functional recovery of mental health consumers. The analysis demonstrates that carers are most concerned with enabling daily living functional recovery, for which the mean value was considerably higher than the personal impact and promoting safety and health regions. In terms of the individual questionnaire items, the issues of most importance are assisting with self-care, worrying about consumers' future, finances and general health, encouraging consumer involvement in activities and concerns over the treatment consumers are receiving. Conclusion Caregiving often came at significant personal cost. The burden that results from caring for mental health consumers could perhaps be alleviated through the expansion of psychiatric disability services, increasing government financial support and providing tailored psychosocial interventions that meet the needs of families.

\section{BACKGROUND}

The deinstitutionalisation of services has seen informal carers becoming increasingly involved in the mental health system. ${ }^{12}$ Carers in adopting these roles face ongoing challenges, which may include advocating on behalf of mental health consumers, crisis management, helping with daily activities and providing financial assistance..$^{3-5}$ The burden associated with assuming these responsibilities, coupled with the impact of witnessing their relative experience mental illness, means that carers often report significant levels of distress. ${ }^{4-7}$

About one-third of mental health consumers' family members experience emotional distress. ${ }^{7} 8$ Such distress may
Strengths and limitations of this study

- To our knowledge, this is the first Australian study to examine mental health carers prioritisation of key elements of caregiving and establish the extent to which particular issues contribute to carer burden.

- Qualitative data are used to provide further insight into the quantitative findings.

Respondent bias may influence our results.

encompass feelings of loss, anxiety and distress. ${ }^{9-11}$ In addition, caregiving may lead to social isolation, reduced work productivity, financial loss and disruption in family routines, which may substantially impair carers' quality of life. ${ }^{911-14}$

Several factors have been identified that influence mental health caregiver burden. Studies have shown that caring for a male mental health consumer leads to significantly higher levels of stress. ${ }^{15}$ Other demographic characteristics that effect burden include lower levels of caregiver education and younger carer age, both of which have been associated with higher levels of depression. ${ }^{16-19}$ Also, supporting consumers who display heightened positive or negative symptoms exacerbates the detrimental impact on carers' quality of life, work efficiency and lost days of work. ${ }^{20}$

Although much of the available literature focuses on adverse consequences, caregiving for mental health consumers also results in beneficial outcomes for carers. Some mental health carers note that supporting consumers has sensitised them to the needs of people with disabilities, enabled them to clarify their priorities in life and has enhanced their resilience. ${ }^{21}$ The sense of satisfaction and meaning that carers find in helping consumers has been associated with higher levels of quality of life. ${ }^{22-24}$

Research has demonstrated that carers contribute importantly to the recovery of mental health consumers. In particular, the involvement of family members in the provision of mental health services has been found 
to decrease consumer relapse and rehospitalisation rates by $20 \%-50 \%{ }^{4}$ Other mental health consumer benefits that may be attributed to supportive family relationships include improved participation in vocational rehabilitation, higher employment rates, enhanced social functioning and reductions in psychiatric symptoms. ${ }^{4}$

To our knowledge, no prior qualitative studies have explored Australian mental health caregiver burden. However, few quantitative studies have examined issues involved with caring for mental health consumers in an Australian context. ${ }^{13} 2526$ The Australian quantitative studies $^{132526}$ on mental health caregiver burden have reflected the results of research conducted in other countries, ${ }^{71527}$ in that they have shown that carers experience social isolation and impaired physical and mental health. To our knowledge, no prior studies in an Australian setting have quantified aspects of mental health caregiving. This information is important since it provides an understanding of the extent to which individual factors influence mental health caregiver burden, and may enable health services to develop interventions that target the factors that contribute most substantially to such burden. Hence, the purpose of this study is to explore Australian mental health carers' experiences through rating the importance of key elements of caregiving and establish the extent to which particular issues contribute to carer burden.

\section{METHODS}

\section{Study design}

This study involves a cross-sectional survey of Australian mental health caregivers.

\section{Survey instrument}

The Involvement Evaluation Questionnaire (IEQ) was used to measure mental health carer burden. ${ }^{27}$ The decision to use the IEQ in this study was based on the findings of a systematic review, which recommended the IEQ as one of the two most superior instruments to assess mental health caregiver burden. ${ }^{28}$ The questionnaire comprises four scales: 1) tension (nine items), which assesses interpersonal difficulties between consumers and carers; 2) supervision (six items), which enquires about carers' monitoring consumer sleep, medicine intake and dangerous behaviour; 3) worrying (six items), which captures details regarding troubling interpersonal like concern about the consumer's future and safety, overall health and quality of healthcare and 4) urging (eight items), which assesses the extent to which carers encourage consumers to undertake general activities and self-care. ${ }^{27}$ Each item is scored on a 5 -point Likert scale (never $=0$, sometimes $=1$, regularly $=2$, often $=3$, always $=4$ ) ${ }^{27}$ Finally, a single openended question allows carers to make comments about their experiences. This question was phrased as follows: 'Multiple choice questions cannot possibly cover all that you have experienced with the person you care for. Please feel free to add any comments you may wish to make in the space below'.

The structure of the IEQ was originally established through subjecting data from a Dutch mental health caregiver population to principal components analysis, which yielded the aforementioned four scales. ${ }^{27}$ The IEQ has subsequently been translated into English and other languages and undergone psychometric testing, across five international sites, comprising an examination of its internal consistency and test-retest reliability. The results demonstrated that the IEQ scales exhibited adequate levels of test-retest reliability, which was evidenced by the intraclass correlation coefficient values ranging from 0.83 to $0.90 .^{27}$ But some of the Cronbach's $\alpha$ values fell out of the ideal range of $0.70-0.80$ proposed by Bland and Altman. ${ }^{29}$ The Cronbach's $\alpha$ values for IEQ scales ranged from 0.75 to 0.84 for the tension scale; 0.68 to 0.82 for the supervision scale; 0.77 to 0.86 for the worries scale and 0.77 to 0.86 for the urging scale. ${ }^{28}$ The range of these Cronbach's $\alpha$ values suggested that it would be worthwhile to re-evaluate the structure of IEQ, using an exploratory method such as smallest space analysis (SSA). ${ }^{30}$ In addition, guidelines for the international translation of health-related outcome measures recommend that exploratory techniques should be used to establish the structure of translated questionnaires. ${ }^{31}$ This guidance further supported the use of SSA to reassess the structure of IEQ.

\section{Recruitment}

All Australian caregivers for mental health consumers were eligible to participate in this study. Twenty-two carer, mental health carer and mental health consumer organisations disseminated study invitation notices on our behalf through Twitter, Facebook, e-newsletters and online sites. We also personally distributed invitation notices through Facebook pages of mental health carer and consumer groups. The invitation notices outlined the purpose of the study and provided the link for the online survey questionnaire. A comprehensive information letter was placed at the beginning of the survey, which the prospective participants were asked to read before starting to answer the survey questions. All responses were anonymous and return of the questionnaire was used to indicate consent. Data were collected from March 2017 to July 2017.

\section{Participant involvement}

Mental health caregivers were not actively involved in the design of this study, but did contribute extensively to the development of the instrument used in this study.

\section{Sample size}

Cochran's formula for continuous variables was used to establish the number of returned questionnaires required to generalise the study findings. ${ }^{32}$ Given that there were approximately 15666 Australian mental health carers, ${ }^{33}$ and incorporating a 5\% level of acceptable risk and 3\% margin of error, it was established that 133 completed 
questionnaires were needed to generalise the study findings.

\section{Data analysis}

The analysis combined quantitative and qualitative approaches. For the quantitative component, data were entered and analysed in the Hebrew University Data Analysis Package V.8. All demographic variables are reported descriptively. Given the lack of robust evidence for the dimensionality of IEQ, smallest space analysis was used to examine the structure of the dataset. SSA was used as it offers numerous advantages over statistical methods such as factor analysis. ${ }^{34}$ Such advantages include: provision of geometric output that is readily comprehensible; derivation of the fewest number of dimensions; results remain invariant under rotation and lack of need to select orthogonal or oblique rotations. ${ }^{345}$ It is an especially robust method that can be used to analyse many different types of data. ${ }^{30} \mathrm{SSA}$ is one of a host of non-metric multidimensional scaling (MDS) methods used to represent relationship measures between variables or items in a low dimensional space. ${ }^{30}$ The SSA programme calculates associations between variables, where the association between any two variables is expressed as the distance between them on a graph such that the smaller the distance between two plotted variables, the stronger the association.

In this instance, SSA was used in an exploratory manner to uncover any hidden structures in the dataset that could be easily identified and displayed visually. ${ }^{36}$ It provides a means for reducing data and in so doing produces a summary of complex data that can be examined and interpreted. Themes or patterns may arise from the visual depiction. A particular cluster of variables, each of which represents a construct or theme that captures something of the carers' experience, are derived from a partitioning of the graph into regions or neighbourhoods.

SSA also produces a measure, the co-efficient of alienation, that demonstrates how well the distances between the points on the two- dimensional SSA plot reflect the correlations between the questionnaire items. ${ }^{37}$ The coefficient of alienation can range from 0 (best fit) to 1 (worst fit), and should be $\leq 0.2$ to be considered satisfactory. ${ }^{37}$ To facilitate comparison between the SSA scales, which contained differing numbers of items, a total scale score was produced by summing the items, which was then divided by the number of items within the scale, after which a mean scale score was derived.

The qualitative aspect of the analysis was based on the thematic analysis methods by Braun and Clarke. ${ }^{38}$ In this study, a theoretical, deductive approach to coding was used as the main purpose of the analysis was to confirm and further illuminate the structures identified in the SSA analysis of the IEQ items. As such, a coding framework was developed wherein the SSA regions served as themes, and the items within each region acted as subthemes. All of the open-ended responses were then systematically analysed line by line and constant comparison was used to map extracts from these responses into the coding framework. Both authors initially reviewed the full set of open-ended responses. One of the authors then mapped the responses into an excel spreadsheet that contained the coding framework. The other author reviewed the conceptual fit of the mapped responses. The authors then met in-person to clarify and further elaborate the themes and subthemes through a consensus-driven discussion.

\section{RESULTS}

The total number of returned questionnaires was 231, of which 122 contained responses to the open-ended question. The respondents' demographic characteristics are displayed in tables 1 and 2. The average age of the respondents was $51.7(\mathrm{SD}=12.3)$ years. Almost all respondents were female $(91.0 \%)$. Respondents tended to be in a long-term relationship or married (59.2\%), and generally lived with their spouse, partner or children $(72.6 \%)$ in metropolitan locations (55.8\%). During the past 4 weeks, most respondents experienced a physical or mental health problem $(75.0 \%)$, for which they most commonly consulted a general practitioner $(68.0 \%)$. In terms of the psychiatric diagnoses for the consumers of whom the respondents supported, the most common were bipolar $(19.9 \%)$ and schizophrenia/schizoaffective disorder $(19.4 \%)$, followed by depression $(10.4 \%)$, personality disorder $(10.0 \%)$ and anxiety disorder $(7.0 \%)$. In addition, about one-third $(32.8 \%)$ of the respondents indicated 'other' for the psychiatric diagnosis, of which two-thirds $(66.6 \%)$ related to the co-occurrence of two or more psychiatric disorders.

\section{Smallest space analysis}

The coefficient of alienation for the SSA was 0.21. Figure 1 displays the two-dimensional plot that resulted from the SSA. An inspection of the plot shows that the items were clustered into three distinct regions. These regions are conceptualised as: 1) promoting the safety and health of mental health consumers; 2) enabling the daily living functional recovery of mental health consumers and 3) impact of caring on caregivers' personal lives. Note that one of the items, 'annoyed others', did not clearly fall into a distinct region, and hence was not included in the interpretation of the findings.

\section{Region 1: promoting the safety and health of mental health} consumers

The region captures some of the concerns of carers which lead them to adopt a more protective stance as a way of promoting the safety and health of consumers for whom they care. Table 3 displays the seven items encapsulated in the promoting safety and health region. The overall mean value for the promoting safety and health region was 1.7. As can be seen from the mean values for the individual items, the respondents are most concerned by their relatives' / friends' general health. Such concern is unsurprising as mental health consumers often experience 
Table 1 Demographics-personal characteristics

Mean (SD)

\begin{tabular}{ll} 
Carer's age $(n=198)$ & $51.7(12.3)$ \\
Consumer's age $(n=199)$ & $41.6(19.1)$ \\
\hline
\end{tabular}

\begin{tabular}{|c|c|}
\hline & Proportion (\%) \\
\hline \multicolumn{2}{|l|}{ Gender } \\
\hline Carer female $(n=201)$ & 91.0 \\
\hline Consumer female $(n=201)$ & 41.8 \\
\hline \multicolumn{2}{|l|}{ Carer relationship status $(n=201)$} \\
\hline Married/long-term relationship & 59.2 \\
\hline Divorced & 18.9 \\
\hline Widowed & 2.0 \\
\hline Unmarried & 13.4 \\
\hline Other & 6.5 \\
\hline \multicolumn{2}{|l|}{ Carer's relationship to consumer $(n=200)$} \\
\hline Mother/father & 43.0 \\
\hline Daughter/son & 15.0 \\
\hline Sister/brother & 6.5 \\
\hline Other relative & 1.0 \\
\hline Wife/husband/partner & 28.5 \\
\hline Friend & 2.5 \\
\hline Other & 3.5 \\
\hline $\begin{array}{l}\text { Carers with physical or mental health } \\
\text { problems in last } 4 \text { weeks }(n=200)\end{array}$ & 75 \\
\hline \multicolumn{2}{|l|}{$\begin{array}{l}\text { Assistance type for physical or mental health } \\
\text { problems in last } 4 \text { weeks }(n=150)\end{array}$} \\
\hline General practitioner/family doctor & 68.0 \\
\hline Social worker/psychologist/psychiatrist & 45.9 \\
\hline Medication & 48.7 \\
\hline Carer support groups & 36.5 \\
\hline Online information & 52.9 \\
\hline Online support & 25.0 \\
\hline
\end{tabular}

Extra expenses over last 4 weeks incurred on behalf of person for whom they care $(n=201)$

\begin{tabular}{ll} 
Professional help for consumer & 36.4 \\
Large expenditures incurred by consumer & 14.3 \\
Damage caused by consumer & 12.1 \\
Consumer's travel expenses & 19.9 \\
Medicine for consumer & 38.5 \\
Paying off consumer debt & 19.9 \\
Other & 20.8 \\
\hline
\end{tabular}

multiple comorbidities, which is captured in the following respondent's statement:

Physical health problems are compounded by mental health. (My) partner also has diabetes, sleep apnoea, irregular heartbeat, high blood pressure, high cholesterol, arthritis, severe hearing loss and more. (Participant 120)
Table 2 Demographics-living arrangements

Proportion (\%)

$\begin{array}{ll}\text { Residential location }(\mathrm{n}=199) & \\ \text { Metropolitan } & 55.8 \\ \text { Regional } & 34.2 \\ \text { Rural } & 10.0 \\ \text { State/territory ( } \mathrm{n}=200) & \\ \text { Australian Capital Territory } & 1.5 \\ \text { New South Wales } & 24.5 \\ \text { Northern Territory } & 4.0 \\ \text { Queensland } & 21.0 \\ \text { South Australia } & 5.5 \\ \text { Tasmania } & 5.0 \\ \text { Victoria } & 17.0 \\ \text { Western Australia } & 21.5\end{array}$

Carer household composition $(n=201)$

$\begin{array}{ll}\text { Live alone } & 8.0 \\ \begin{array}{l}\text { Live with spouse/partner/ } \\ \text { children }\end{array} & 72.6 \\ \begin{array}{l}\text { Live with parents/sisters/ } \\ \text { brothers }\end{array} & 4.0 \\ \begin{array}{l}\text { Live with other relatives } \\ \text { Live with friends }\end{array} & 3.0 \\ \text { Other } & 0.5 \\ \begin{array}{l}\text { Carer time spent living with } \\ \text { consumer last } 4 \text { weeks ( } \mathrm{n}=189 \text { ) }\end{array} & 11.9 \\ \text { Entire } 4 \text { weeks } & 67.2 \\ \text { None } & 25.4 \\ \text { Some } & 7.4 \\ & \text { (mean number of days=8.3) }\end{array}$

$\begin{aligned} & \text { Personal or telephone contact } \\ & \text { per week between consumer and } \\ & \text { carer }\end{aligned}$
$\begin{array}{ll}>32 \text { hours } & 51.8 \\ 17-32 \text { hours } & 8.0 \\ 9-16 \text { hours } & 12.1 \\ 5-8 \text { hours } & 17.6 \\ <5 \text { hours } & 10.6\end{array}$

The item with the next highest mean value in this region reflected concern about the healthcare their relatives/friends is receiving. The qualitative material showed that respondents are worried about several aspects of the delivery of mental healthcare. Many respondents stated that it is difficult to access services, especially in regional or rural areas, for example:

Help for mental illness is practically non-existent in rural areas. The nearest mental health facility is a two hour trip away and it hasn't been helpful at all. Firstly, I have found the person presenting is interviewed by an intake officer, and that intake officer 


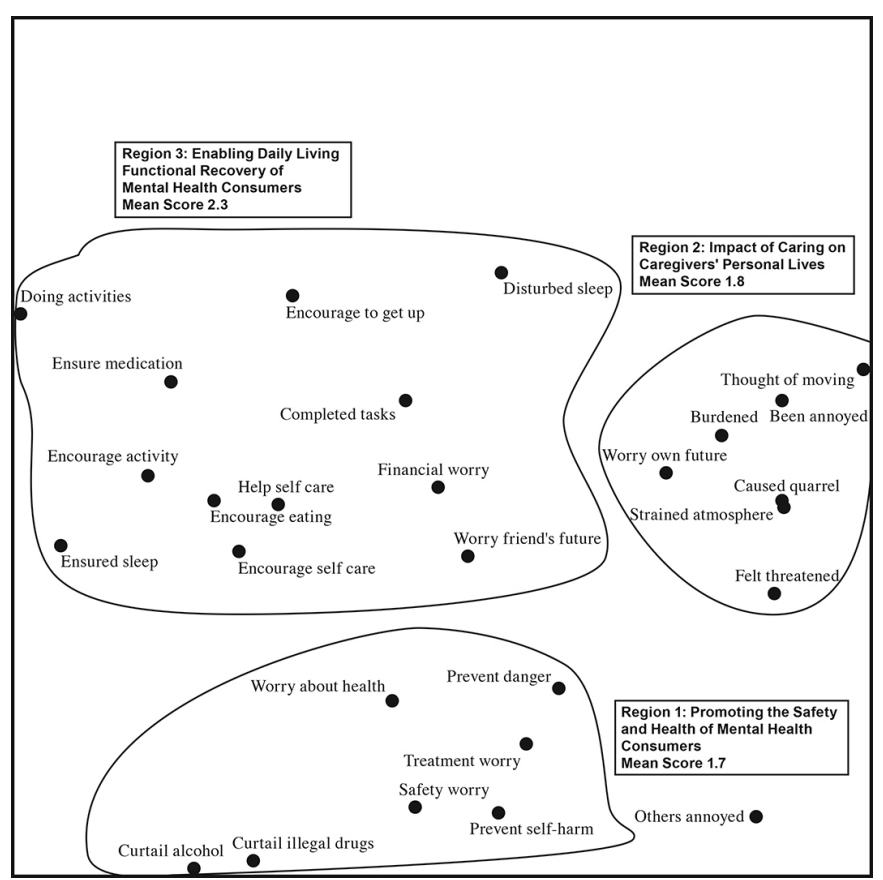

Figure 1 Regions identified through smallest space analysis.

makes a decision based possibly upon the criteria for the day; if all the boxes aren't checked, the person presenting gets no help. This has been my experience with my family member, turned away because all the boxes weren't checked and terrible consequences followed. (Participant 42)

In some cases, the lack in continuity of care is the primary concern, which undermined the relationship between carers and health professionals, and left carers' feeling isolated and concerned:

...the mental health system is that it is so disjointed and I find it hard who to trust with our information and finding someone that cares enough to follow-up and support me. (Participant 57)

Inadequate government support is often thought to detrimentally impact on the quality of mental healthcare. The paucity of support meant that the onus for care fell on the respondents: 'governments have let us down immeasurably and as a result the burden has been immense'. Some respondents are left feeling hopeless, but others were eventually able to obtain adequate mental healthcare:

Getting help for my son and guidance for me to help him has been an arduous and very lengthy process. If I wasn't as steadfast and committed I may have given up several times after being told 'NO'. I have had to struggle to find the few people that are now involved in my son's care, and they are brilliant most of the time. But they didn't all come to help us, I had to research hard to find them over years. (Participant 84)

The item that enquired about carers' worry in regard to their friends' / relatives' safety also recorded a relatively high mean score. However, the phrasing used for this item meant that it is difficult to identify explicit safety issues. Finally, the mean scores for the items that captured details about concern over self-harm, alcohol and illegal substances are relatively low. But these issues are nonetheless a source of substantial concern for some respondents, as the following excerpt demonstrates:

Alcohol in the quantities that he consumes is totally destructive. It is an overwhelming burden to have a child of any age, want to destroy themselves this way. So in answer to the question 'Do I guard him from self-harm, consuming drugs and excessive alcohol?' the answer is a huge yes, always!-but I cannot stop him, and I cannot control him, only encourage, support and guide him to the best of my ability. (Participant 84)

Region 2: impact of caring on caregivers' personal lives

The second neighbourhood of items illustrated on the two-dimensional plot emphasises the personal impact of caring on carers' lives (table 4 ). The overall mean value for this region was 1.8. The mean values for the individual items in this region indicate that the respondents are most troubled by the carer burden that resulted from their relatives'/friends' mental health problems. Some respondents noted that caring for mental health consumers is accompanied by a sense of loss that had both physical and mental health consequences:

It would be useful to look at the issue of ambiguous loss for family carers, particularly for those who are long-term family carers. This is something that is

Table 3 Promoting safety and health

\begin{tabular}{ll}
\hline Item & Mean (SD) \\
\hline Have you guarded your relatives/friends from self-inflicted harm? & $1.1(1.0)$ \\
\hline Have you guarded your relatives/friends from committing dangerous acts? & $1.3(1.0)$ \\
\hline Have you guarded your friends/relatives from drinking too much alcohol? & $1.0(1.2)$ \\
\hline Have you guarded your friends/relatives from taking illegal drugs? & $0.8(1.2)$ \\
Are you worried about the type of help/treatment your friends/relatives is receiving? & $2.5(1.2)$ \\
Are you worried about your friends'/relatives' safety? & $2.3(1.2)$ \\
\hline Are you worried about your friends'/relatives' general health? & $2.8(1.1)$ \\
\hline
\end{tabular}




\begin{tabular}{ll}
\hline Table 4 Personal impact & \\
\hline Item & Mean (SD) \\
\hline Has the atmosphere been strained between you both, as a consequence of your friends'/relatives' behaviour? & $2.1(1.1)$ \\
\hline Has your friend/relative caused a quarrel? & $1.9(1.0)$ \\
\hline Have you been annoyed by your friends'/relatives' behaviour? & $2.1(1.0)$ \\
\hline Have you felt threatened by your friends'/relatives' behaviour? & $0.9(0.9)$ \\
\hline Have you thought of moving out as a result of your friends'/relatives' behaviour? & $1.2(1.2)$ \\
Are you worried about your own future? & $1.9(1.2)$ \\
\hline Have your friends'/relatives' mental health problems been a burden to you? & $2.3(1.2)$
\end{tabular}

under-identified in the area of impact on carers and mental health and yet, anecdotally I know from my peers that it has a very real and very significant impact on people's physical (autoimmune disorders) and mental (grief and depression) health. (Participant 7)

Another issue that several respondents noted has an impact on physical and mental health is the substantial amount of time devoted to caring, which results in social isolation, less time given to other family members and neglect of their own well-being. As one respondent put it:

You feel very alone. You just wish you could have time to yourself. You don't want to walk on eggshells any more. You want to celebrate your other kids and spend time with them but your attention is always diverted towards this one. When I'm not with them I worry are they ok. I would just like to be by myself without having to worry. (Participant 74)

This sense of isolation in some instances was compounded by a lack of support from family members:

I do find I isolate and insulate myself as my family won't discuss it, they don't want to know as it's too stressful. My son's father abandoned him 3 years ago as he cannot cope with his mental illness. (Participant 17)

In addition to the physical and mental health consequences, respondents also often drew attention to the financial burden associated with caregiving. Time spent on caring meant that respondents are unable to participate fully in the workforce. This directly impacts materially on the respondents' 'own future', which is another of the items in the personal impact region that has a relatively high mean value. Other concerns that carers hold about their future involve the effect on career prospects and lifestyle, as can be seen from the following excerpts:

I was extremely depressed when I was a full-time carer. I deferred university, failed subjects and lost touch with my own aspirations. (Participant 73)

It's hard to express the impact it has on my life. It's the day-to-day impact, the need to be there or in contact at anytime. The need to consider her needs in all my decisions. The impact on my future plans-I would dearly love to go live overseas, but my mother is still relatively young, and as much as it feels wrong to say this, she may live a long time and make my dreams impossible. (Participant 67)

The remaining items in the personal impact region captured details about interpersonal tension between carers and mental health consumers. Relatively high mean values were reported for the items that enquired about the strained atmosphere, quarrels and annoyance at the relatives'/friends' behaviour. These issues could be especially distressing, as one respondent noted:

It's more than hard-dealing with this is something one can't explain and the emotional verbal assaults we get from him is soul destroying. (Participant 16)

Given the often substantial nature of the ongoing interpersonal tension, especially for those carers undertaking this work on a long-term basis, it would be understandable if carers discontinued their support of mental health consumers. Yet some carers demonstrate extraordinary levels of empathy and resilience, as was the case with this respondent:

Caring for my husband is a tremendous burden. His episodes are full of emotional abuse, anger coupled with destruction of property and then feelings of the very deepest self-loathing. For me though, it's given me a greater capacity to improve myself and to experience empathy when it's not the natural response in this situation. No matter how much he hurts me, and believe me he really does, it's nothing compared to how much he is hurting and hates himself. My heart breaks for him. He suffers from a biological illness that affects every part of him. His relationships, his day-to-day life. Underneath the imbalance is the reason I married him. (Participant 24)

Region 3: enabling daily living functional recovery of mental health consumers

The third area clearly identified in the space emphasises the carers' role in the recovery journey for consumers. Table 5 displays the 12 items encapsulated in the enabling daily living functional recovery region. The overall mean value for this region was 2.4. Many of the items in this region enquire about aspects of caring that can be conceptualised as supporting social and functional 
Table 5 Enabling daily living functional recovery

\begin{tabular}{|c|c|}
\hline Item & Mean (SD) \\
\hline Have you encouraged your friends/relatives to get up in the morning? & $1.8(1.2)$ \\
\hline Have you ensured your friends/relatives received sufficient sleep? & $2.0(1.1)$ \\
\hline Are you worried about how your friends/relatives would manage financially if you were no longer able to help? & $2.7(1.3)$ \\
\hline Are you worried about your friends'/relatives' future? & $3.0(1.1)$ \\
\hline Have you helped your friend/relative to take proper care of herself/himself? & $2.7(1.1)$ \\
\hline Have you encouraged your friends/relatives to eat enough? & $2.2(1.3)$ \\
\hline Have you encouraged your friends/relatives to undertake some kind of activity? & $2.5(1.1)$ \\
\hline $\begin{array}{l}\text { Have you accompanied your friends/relatives on some sort of outside activity, because your friends/relatives } \\
\text { did not dare go out alone? }\end{array}$ & $2.0(1.3)$ \\
\hline
\end{tabular}

components of mental health recovery. In terms of functional recovery, encouraging and helping mental health consumers with self-care and normal tasks, and concerns about consumers' ability to manage financially, are the items with highest mean values. Assisting with self-care and normal tasks could be onerous and is an area in which professional support would be beneficial, as the following excerpts demonstrate:

I feel it's a battle I am fighting but losing. I struggle with him to look after himself personally to do basic hygiene (shower, brush teeth, change clothes) I am now looking at groups online to seek help not only him but myself. (Participant 16)

Ironing, vacuum cleaning, cleaning floors, and all other household duties is not leaving me with any time... her inability to accept help in her personal washing and getting into her clothing makes for a lot of time lost in a day. I am about to seek help from the professionals. (Participant 70)

Financial concerns are one of the most frequently raised issues in the open-ended responses. A key element of these concerns is the inadequate level of government financial assistance:

He is on the disability support, and after rent, has only less then $\$ 200$ a fortnight to feed himself, buy petrol and food, feed dogs... so guess who pays for the necessities? It is quite a strain and the National Disability Insurance Scheme has not been able to assist in the way he would like. (Participant 85)

The items that captured information about aspects of social recovery generally had lower mean values than the functional recovery items. And while the importance of facilitating social inclusion was noted, it appears to be an issue that is difficult to resolve. As one respondent put it:
Exhaustion is constant as my partner relies on me totally for his social support and talks non-stop. (Participant 8)

Finally, in the enabling daily living functional recovery region, the second highest mean value was recorded for the item that asked the respondents if they are worried about their relatives'/friends' future. It is unsurprising that carers are often concerned about the mental health consumers' prospects. As the above material has shown, it is not uncommon for mental health consumers to experience social isolation and struggle with daily activities and finances. The journey towards recovering pieces of consumers' lives clearly requires time and is difficult, but could nonetheless be gratifying for carers:

It is tough at times, but you get some little rewards along the way when they achieve things on their own. (Participant 78)

\section{DISCUSSION}

The regions identified through the SSA provide a basis to understand the manner in which carers prioritise issues that arise in supporting mental health consumers. The analysis demonstrates that carers are most concerned with enabling daily living functional recovery, for which the mean value is considerably higher than the personal impact and promoting safety regions. In terms of the individual questionnaire items, the issues of most importance are assisting with self-care, worrying about consumers' future, finances and general health, encouraging consumer involvement in activities and concerns over the treatment consumers are receiving.

The high level of concern that respondents report about daily living functional recovery suggests that the provision of services that assist with these issues may contribute to the reduction of caregiver burden. Psychiatric disability 
services are available in the community throughout Australia to help carers and mental health consumers with tasks like activities of daily living, housing, recreational and social activities and employment opportunities. ${ }^{39}$ However, the extent to which Australian carers and mental health consumers access these services is presently unknown. Further studies might be beneficial in identifying whether the provision of psychiatric disability support services adequately address the needs of mental health caregivers in regard to assistance with consumers daily living functional recovery.

It was unsurprising to find that financial concerns figure prominently in the open-ended responses and also have a high mean item rating. Many mental health carers forgo employment or reduce their working hours while supporting consumers. ${ }^{40}{ }^{41}$ In Australia, modest income support payments are available to mental health carers who do not work, but these payments are only accessible to a small proportion of carers. ${ }^{4042}$ The hardship that results from the lack of adequate financial assistance is further compounded by the often substantial level of financial support that carers provide to mental health consumers. $^{40}$

Our findings show that health professionals also have an important role to play in alleviating mental health caregiver burden. Concerns over the provision of metal healthcare are highlighted in this study, especially in regard to being isolated from the care that consumers were receiving. Such issues reflect the results of other mental health carer studies that have been conducted in Australia and within the UK. ${ }^{6}{ }^{43}$ To some extent, the concern that carers experience in regard to the provision of services might be lessened through exploring and incorporating their views in planning and delivering mental healthcare. ${ }^{4}$

\section{Limitations}

The demographic details of Australian mental health carers vary considerably between studies. It is therefore difficult to develop a standardised profile of Australian mental health caregivers. However, the demographic characteristics of the carers in this study are highly consistent with the details reported in the most recent study of Australian mental health caregivers, which to some extent supports the generalisability of our findings. ${ }^{40}$ Finally, our value for the coefficient of alienation equalled 0.21 , which was marginally outside of the range of $0.15-0.20$ that is considered to represent a good fit. ${ }^{37}$ That said, the coefficient of alienation should be interpreted in light of the SSA visual structure, which in the case of our study clearly delineated distinct regions. ${ }^{37}$

\section{CONCLUSION}

Our findings demonstrate that carers' prioritise roles that promote the recovery of mental health consumers. However, such caregiving often incurs significant personal cost. The burden that results from caring for mental health consumers could perhaps be alleviated through the expansion of psychiatric disability services, increasing government financial support and involving families more closely in the planning and delivery of mental health services. Such assistance would improve the circumstances of caregivers, and would probably enhance the recovery of mental health consumers.

Contributors PM contributed to the conceptualisation, conduct, analysis and reporting of this study. NJS contributed to the conceptualisation, conduct, analysis and reporting of this study.

Funding The authors have not declared a specific grant for this research from any funding agency in the public, commercial or not-for-profit sectors.

\section{Competing interests None declared.}

Patient consent for publication Not required.

Ethics approval The Murdoch University Human Research Ethics Committee granted ethical approval for this study (approval number 2016/215).

Provenance and peer review Not commissioned; externally peer reviewed. Data sharing statement No additional data are available.

Open access This is an open access article distributed in accordance with the Creative Commons Attribution Non Commercial (CC BY-NC 4.0) license, which permits others to distribute, remix, adapt, build upon this work non-commercially, and license their derivative works on different terms, provided the original work is properly cited, appropriate credit is given, any changes made indicated, and the use is non-commercial. See: http://creativecommons.org/licenses/by-nc/4.0/.

\section{REFERENCES}

1. Gutiérrez-Maldonado J, Caqueo-Urízar A, Kavanagh DJ. Burden of care and general health in families of patients with schizophrenia. Soc Psychiatry Psychiatr Epidemiol 2005;40:899-904.

2. Sales E. Family burden and quality of life. Qual Life Res 2003;12(Suppl 1):33-41.

3. Morrison P, Stomski NJ. Carers' perspectives on mental health consumers' use of antipsychotic medication: a multidimensional scalogram analysis. Contemporary Family Therapy 2017.

4. McFarlane WR. Family interventions for schizophrenia and the psychoses: a review. Fam Process 2016;55:460-82.

5. Kuipers E. Time for a separate psychosis caregiver service? J Ment Health 2010;19:401-4.

6. Stomski NJ, Morrison P. Carers' involvement in decision making about antipsychotic medication: a qualitative study. Health Expect 2018;21:308-15.

7. Magliano L, Fadden G, Economou M, et al. Family burden and coping strategies in schizophrenia: 1-year follow-up data from the BIOMED I study. Soc Psychiatry Psychiatr Epidemiol 2000;35:109-15.

8. Möller-Leimkühler AM, Wiesheu A. Caregiver burden in chronic mental illness: the role of patient and caregiver characteristics. Eur Arch Psychiatry Clin Neurosci 2012;262:157-66.

9. Cormac I, Tihanyi P. Meeting the mental and physical healthcare needs of carers. Advances in Psychiatric Treatment 2006;12:162-72.

10. Oyebode J. Assessment of carers' psychological needs. Advances in Psychiatric Treatment 2003;9:45-53.

11. Kuipers E, Onwumere J, Bebbington P. Cognitive model of caregiving in psychosis. Br J Psychiatry 2010;196:259-65.

12. Morrison P, Stomski N. Experiences of family carers for persons using antipsychotic medication. Aust N Z J Fam Ther 2017;38:498-513.

13. Hayes L, Hawthorne G, Farhall J, et al. Quality of life and social isolation among caregivers of adults with schizophrenia: policy and outcomes. Community Ment Health J 2015;51:591-7.

14. Magliano L, Fiorillo A, De Rosa C, et al. Family burden in longterm diseases: a comparative study in schizophrenia vs. physical disorders. Soc Sci Med 2005;61:313-22.

15. Magaña SM, Ramírez García Jl, Hernández MG, et al. Psychological distress among latino family caregivers of adults with schizophrenia: the roles of burden and stigma. Psychiatr Serv 2007;58:378-84.

16. Papastavrou E, Kalokerinou A, Papacostas SS, et al. Caring for a relative with dementia: family caregiver burden. J Adv Nurs 2007;58:446-57. 
17. Papastavrou E, Charalambous A, Tsangari H, et al. The cost of caring: the relative with schizophrenia. Scand J Caring Sci 2010;24:817-23.

18. Finch BK, Kolody B, Vega WA. Perceived discrimination and depression among Mexican-origin adults in California. J Health Soc Behav 2000;41:295-313.

19. González HM, Haan MN, Hinton L. Acculturation and the prevalence of depression in older Mexican Americans: baseline results of the Sacramento Area Latino Study on Aging. J Am Geriatr Soc 2001;49:948-53.

20. Rabinowitz J, Berardo CG, Bugarski-Kirola D, et al. Association of prominent positive and prominent negative symptoms and functional health, well-being, healthcare-related quality of life and family burden: a CATIE analysis. Schizophr Res 2013;150:339-42.

21. Gupta A, Solanki R, Koolwal G, et al. Psychological well-being and burden in caregivers of patients with schizophrenia. Int J Med Sci Public Health 2015;4:70-6.

22. Kate N, Grover S, Kulhara P, et al. Relationship of caregiver burden with coping strategies, social support, psychological morbidity, and quality of life in the caregivers of schizophrenia. Asian J Psychiatr 2013:6:380-8

23. Kulhara P, Kate N, Grover S, et al. Positive aspects of caregiving in schizophrenia: a review. World J Psychiatry 2012;2:43-8.

24. Doval N, Sharma E, Agarwal M, et al. Experience of caregiving and coping in caregivers of schizophrenia. Clin Schizophr Relat Psychoses 2016;12.

25. Poon AWC, Curtis J, Ward P, et al. Physical and psychological health of carers of young people with first episode psychosis. Australas Psychiatry 2018;26:184-8.

26. Kenny P, King MT, Hall J. The physical functioning and mental health of informal carers: evidence of care-giving impacts from an Australian population-based cohort. Health Soc Care Community 2014;22:646-59.

27. Wijngaarden van B SAH, Koeter M, Vazquez-Barquero JL, et al. Caregiving in schizophrenia: development, internal consistency and reliability of the Involvement Evaluation Questionnaire-European Version. EPSILON Study 4. European Psychiatric Services: Inputs Linked to Outcome Domains and Needs. Br J Psychiatry Suppl 2000;39:s21-s27.

28. Vella SL, Pai N. The measurement of burden of care in serious mental illness: a qualitative review. Aust N Z J Psychiatry 2013;47:222-34.
29. Bland JM, Altman DG. Cronbach's alpha. BMJ 1997;314:572.

30. Guttman R, Greenbaum CW. Facet theory: Its development and current status. European psychologist 1998;3:13.

31. Gandek B, Ware JE. Methods for validating and norming translations of health status questionnaires: the IQOLA Project approach. International Quality of Life Assessment. J Clin Epidemiol 1998;51:953-9.

32. Barlett JE, Kotrlik JW, Higgins CC. Organizational research: determining appropriate sample size in survey research. ITLPJ 2001;19:43

33. Morgan VA, Waterreus A, Jablensky A, et al. People living with psychotic illness in 2010: the second Australian national survey of psychosis. Aust N Z J Psychiatry 2012;46:735-52.

34. Bloombaum M. Doing smallest space analysis. J Conflict Resolut 1970;14:409-16.

35. Maslovaty N, Marshall AE, Alkin MC. Teachers' perceptions structured through facet theory: smallest space analysis versus factor analysis. Educ Psychol Meas 2001;61:71-84.

36. Borg I, Groenen PJF, Mair P. Applied Multidimensional Scaling. Applied Multidimensional Scaling: Springer, 2013:81-6.

37. Katz E, Haas H, Gurevitch M. On the use of the mass media for important things. Am Sociol Rev 1973;38:164-81.

38. Braun V, Clarke V. Using thematic analysis in psychology. Qual Res Psychol 2006;3:77-101.

39. Edwards R, Fisher KR, Tannous K, et al. Housing and associated support for people with mental illness or psychiatric disability. New South Wales: Griffith University, 2009

40. Diminic S, Hielscher E, Lee YY, et al. The economic value of informal mental health caring in Australia: technical report. Brisbane: The University of Queensland, 2016.

41. ABS. Caring in the community. 2014 http://www.abs.gov.au/ AUSSTATS/abs@.nsf/DetailsPage/4436.02012? (Accessed 14 Feb 2018).

42. RANZCP. Improved assessment process for carer payment and carer allowance. 2015 https://www.ranzcp.org/Files/Resources/ Submissions/4346-RANZCP-SUB-President-to-K-Paton-re-DSSCarer.aspx (Accessed 12 Feb 2018).

43. Askey R, Holmshaw J, Gamble C, et al. What do carers of people with psychosis need from mental health services? Exploring the views of carers, service users and professionals. J Fam Ther 2009;31:310-31. 